\title{
Proposed legislation on enduring powers of attorney for healthcare decisions and living wills: A legal lifeboat in a sea of uncertainty?
}

\author{
A Strode, BA, LLB, LLM, PhD; S Bhamjee, LLB, LLM; S Soni, LLB, LLM; C Badul, LLB, LLM, PhD \\ School of Law, College of Law and Management Studies, University of KwaZulu-Natal, Pietermaritzburg, South Africa
}

Corresponding author: A Strode (strodea@ukzn.ac.za)

\begin{abstract}
Medical advances have created a range of life-saving or life-prolonging treatments that enable life to be extended artificially. The South African National Health Act provides that a patient has the right to refuse treatment: therefore, in circumstances where they have capacity, they may refuse or request the withdrawal of treatment. Where they lack capacity, the decision will have to be made by partners or family members on their behalf. This raises complex ethicolegal questions around who may act on their behalf, the nature of the decisions they may take and how they should make such choices. In recent years, there has been advocacy for the signing of living wills (an advance health directive setting out a patient's wishes should they lack capacity in the future). However, to date there is still no legal certainty regarding such documents. Recently, a draft private member's Bill was gazetted for public comment. It is envisaged that the Bill will be introduced into the National Assembly at some point in 2019 as an amendment to the National Health Act. However, it is unclear when this will occur. If passed, it will ensure the full legal recognition of living wills, and enable patients to enter into a durable power of attorney for healthcare decisions, in terms of which they give another person the authority to make health decisions on their behalf. This article sets out the current ethicolegal position regarding decision-making on the withdrawing or withholding of patient care. It describes the contents of the draft Bill, and evaluates the extent to which it will address current gaps in the ethicolegal framework.
\end{abstract}

S Afr J Bioethics Law 2019;12(2):84-86. https://doi.org/10.7196/SAJBL.2019.v12i2.687

Medical advances have created a range of life-saving or life-prolonging treatments that enable life to be extended artificially. ${ }^{[1]}$ In this context, doctors are now having to assist patients and families to make end-of-life choices, such as whether to start or to withdraw health interventions. The South African (SA) National Health Act No. 61 of 2003 provides that a patient has the right to refuse treatment: ${ }^{[2]}$ therefore, in circumstances where they have capacity, they may refuse or request the withdrawal of treatment. In cases where they lack capacity, the decision will have to be made by partners or family members on their behalf. The second scenario raises complex ethicolegal questions around who may act on behalf of the patient, the nature of the decisions they may take and how they should make such choices while still respecting the autonomy of the patient.

In recent years, there has been advocacy for the signing of living wills (an advance health directive setting out a patient's wishes should they lack capacity in the future). ${ }^{[3]}$ However, to date there has been no legal certainty regarding such documents. ${ }^{[4]}$ This is not only a patient issue, as doctors acting in such situations have to be mindful of potential civil or criminal liability for failing to preserve life. ${ }^{[5]}$ This has been summed up by the SA Law Reform Commission (SALRC) as follows:

'Doctors are ... afraid of being exposed to civil claims, criminal prosecution and professional censure should they withhold life support systems ... which may inadvertently or otherwise shorten the patient's life, even if they are merely complying with the wishes of the patient.'[5]
The law and ethical guidelines deal with some, but not all, of these questions, leaving a legal lacuna and making the situation uncertain for both patients and medical practitioners. Recently, a draft private member's Bill was gazetted for public comment. ${ }^{[6]}$ It is envisaged that the Bill will be introduced into the National Assembly at some point in 2019 as an amendment to the National Health Act. ${ }^{[6]}$ If passed, it will ensure the full legal recognition of living wills and enable patients to enter into a durable power of attorney for healthcare decisions, in terms of which they give another person the authority to make health decisions on their behalf. ${ }^{[6]}$

This article sets out the current ethicolegal position regarding decision-making on the withdrawing or withholding of patient care. It describes the contents of the Bill, and evaluates the extent to which it will address current gaps in the ethicolegal framework.

\section{Current ethicolegal position on end-of-life decisions by patients lacking legal capacity}

To date, there are no statutory provisions that deal directly with endof-life decisions by incapacitated patients. This is the case despite this issue coming before our courts as long ago as $1992 .{ }^{[4]}$ Importantly, in the Clarke v Hurst NO and Others matter, the court allowed the patient's wife to be appointed as his curator and to authorise the cessation of his treatment, as he was in a permanent vegetative state. ${ }^{[4]}$ It also ordered that she be indemnified from possible criminal prosecution in relation to her actions (the withdrawing of artificial 
nutrition) that would lead to his premature death. ${ }^{[4]}$ The court in this instance did not make a finding on the legality of the patient's preexisting living will. ${ }^{[3]}$ It did, however, note that there was a lacuna in our law regarding the legal status of such a document. ${ }^{[4]}$

Six years later, in 1998, the SALRC released a report on 'Euthanasia and the artificial preservation of life. ${ }^{\prime[5]}$ The SALRC recommended the adoption of new legislation to deal expressly with, among other issues, the legal status of living wills. ${ }^{[5]}$ To date, parliament has taken no steps to act on this recommendation.

The National Health Act passed in 2003 does in part deal with this issue, as it details the rights and duties relating to consent to medical treatment in sections 6 - 9. ${ }^{[2]}$ It establishes four key principles. Firstly, a health service may not be provided without consent, except in specified circumstances. Secondly, consent must be given by a person with legal capacity. If the person lacks capacity, another person must act on his or her behalf. Thirdly, before consenting, the patient must be informed of his or her health status, treatment options and the general benefits, risks and consequences of these treatment options, and right to refuse treatment. Fourthly, patients have the express right to refuse any treatment. ${ }^{[2]}$

The Act provides that proxy consenters can act on behalf of a patient without legal capacity if:

(i) they have been nominated in advance by the patient in a written agreement; or

(ii) a court or a law authorises such an action; for example, a parent acting on behalf of their minor child; or

(iii) they are the patient's spouse or partner, parent, grandparent, adult child or brother or sister. ${ }^{[2]}$

Although there is an absence of specific laws on advance health directives, there are ethical guidelines that deal with end-of-life decisions. ${ }^{[1,3]}$ The Health Professions Council of SA's 'Guidelines for the withholding and withdrawing of treatment' are based on the broad ethical principle that doctors may not harm their patients. ${ }^{[1]}$ According to these guidelines, any deliberate or intentional attempt to end life would be both unlawful and unethical. ${ }^{[1]}$ Nevertheless, a doctor 'may alleviate the suffering of a terminally ill patient by withholding treatment, i.e. allowing the natural process of death to follow its course. ${ }^{\text {[1] }}$

These ethical guidelines expressly recognise living wills and the contents therein. ${ }^{[1]}$ They provide that the wishes expressed in such a document, or any other advance directive, are to be respected. ${ }^{[1]}$ The decision to withdraw care is conceptualised as a team decision between the healthcare professionals and the family. ${ }^{[1]}$ The yardstick for all decisions ought to be the best interests of the patient. ${ }^{[1]}$ The only procedural requirement is an obligation on the doctor to document the decision and the reason for it in the patient's file. ${ }^{[1]}$

\section{National Health Amendment Bill}

The 2018 National Health Amendment Bill proposes an amendment to the existing National Health Act. ${ }^{[6]}$ It has the following aims: firstly, to provide for the legal recognition of two types of advance healthcare directives, namely, a 'living will' and a 'durable power of attorney for healthcare,; ; ${ }^{\prime[]}$ secondly, to prescribe the purpose, scope and format for these documents; ${ }^{[6]}$ thirdly, to confirm that an authorised proxy consenter's decision or the contents of a living will may not be overridden; ${ }^{[6]}$ and fourthly, to provide that a medical practitioner acting upon these directives be immune from criminal and civil prosecutions for any actions taken in terms of the Bill. ${ }^{[6]}$

The proposed amendment creates two mechanisms to facilitate the ongoing recognition of the patient's views regarding end-oflife decisions even when he or she no longer has the legal capacity to express these views in person. These mechanisms are a durable power of attorney for healthcare decisions, and a living will. ${ }^{[6]}$ Any adult (aged $>18$ years) who is of 'sound mind' may prepare either future directive, provided that they comply with the requirements for such documents. ${ }^{[6]}$ These documents will then come into operation when the person is incapacitated and an end-of-life decision needs to be made. ${ }^{[6]}$

If a patient with legal capacity enters into a durable power of attorney on healthcare decisions, in the format stipulated, it requires him or her to nominate any third party to make decisions on his or behalf when incapacitated. ${ }^{[6]}$ The bearer of a durable power of attorney may make decisions regarding (i) the refusal of treatment, and (ii) organ donation. ${ }^{[6]}$ In other words, this power of attorney gives the nominated person the authority to make end-of-life decisions if the patient is incompetent to do so themselves. The decisions made by the nominated person are final, and may not be overridden. ${ }^{[6]}$ The power of attorney comes into effect if the patient becomes ill and is unable to make or communicate healthcare decisions him/herself. ${ }^{[6]}$ The only limit on this power is that the Bill requires the bearer of the power of attorney to consider any medical advice from the doctor who is responsible for the patient's treatment. ${ }^{[6]}$

In the case of the other document, if an adult patient with legal capacity prepares a living will as per the format required, this document sets out their express wishes regarding certain endof-life choices, including that they are not to receive any 'future potentially life-sustaining medical treatment or procedure.!6] This can include a refusal to accept artificial nutrition, hydration, dialysis, any intravenous tube or machine support. ${ }^{[6]}$ The treating medical doctor, before acting on the contents of the living will, must ensure that:

(i) the patient's medical condition is irreversible, because they are terminally ill with an incurable condition, in a permanent vegetative state or irreversibly unconscious;

(ii) the living will is authentic; and

(iii) the family of the patient have been informed of the living will's existence. ${ }^{[6]}$

Again, the contents of the living will must be complied with, and may not be overridden. ${ }^{[6]}$

\section{Discussion}

In the last two decades, there have been significant changes to the nature of the patient-doctor relationship. Our law on consent is now fundamentally based on the principle of patient autonomy rather than medical paternalism. ${ }^{[7]}$ This is in line with the SA Constitution, which contains the right to bodily and psychological integrity. ${ }^{[8]}$ This is a right to autonomy over one's body and one's health choices..$^{[9]}$ In this context, ethicolegal questions arise because there is no statutory framework dealing with the manner in which an incapacitated patient's right to autonomy can best be promoted when end-oflife decisions need to be taken. The courts, the National Health Act 
and ethical norms provide some guidance, but without a statutory framework, the possibility of civil and criminal liability continues to exist. Three key questions remain unanswered in our current framework:

(i) Can a patient's right to refuse treatment continue to exist when they lack the legal capacity to exercise the right, i.e. can this right be exercised by a third party?

(ii) Are living wills or advanced directives that contain the patient's wishes legally recognised? and

(iii) Are doctors indemnified from criminal prosecution or civil claims if they act in accordance with ethical guidelines on withholding or withdrawing treatment?

The proposed amendments to the National Health Act are to be welcomed, as they are the first attempt to table legislation on this issue. They also address a number of the outstanding issues listed above. It is submitted that if adopted, the amendment will bring legal certainty and facilitate a principled way forward.

If we examine the first issue, the right of an incapacitated person to refuse treatment, the National Health Act, as stated above, recognises the right of a patient to consent to or refuse treatment. ${ }^{[2]}$ If a patient lacks capacity, consent must be provided in accordance with the Act, which allows for proxy consent. In the definition of 'user' (patient) in section 1 of the Act, there is a list of proxy consenters. ${ }^{[2]}$ It is submitted that this implies that when the proxy consenter acts on behalf of the patient/user, they are standing in the patients'shoes, and are therefore able to exercise any rights due to the patient, including the right to refuse treatment. The proposed amendment confirms this position by expressly enabling patients to use one of two mechanisms to ensure that their right to refuse treatment is respected. In this way, the proposed amendment takes this autonomy right further, by allowing a competent person to document decisions about possible future healthcare choices on which healthcare workers will be required to act. This approach is also in line with the outcome in the Clarke $v$ Hurst NO and Others, where the court accepted that treatment could be withdrawn. ${ }^{[4]}$

With regard to the second question, on the legality of living wills, as stated above, the Bill, if passed, will ensure the full legal recognition of both living wills and enduring powers of attorney. This means that for the first time, we will have legal certainty regarding these documents. Furthermore, the wishes of the incapacitated patient cannot be overridden. This is in line with the recent case of $A B$ and Another v Minister of Social Development, where the Constitutional Court noted that when a person has the right to make an autonomous choice, it is the decision that enjoys protection, rather than the actual choice. ${ }^{[10]}$

The final outstanding question relates to the indemnification of doctors. Again, the proposed amendment answers this question clearly by providing that there will be no civil or criminal liability for actions taken in terms of Bill. ${ }^{[2]}$ This is very significant, as although ethical guidelines authorise doctors to act on living wills, the guidelines are subservient to the law. ${ }^{[1]]}$ For example, in Pandie $v$ Isaacs, the court observed that 'guidelines do not have the status of law and are merely part of the evidential material to be weighed in determining the standards reasonably to be observed by doctors'.[12] The proposed amendments fill this legal lacuna. They are also, at the level of principle, substantially similar to the well-accepted ethical guidelines developed by the medical profession.

\section{Conclusion}

Medical science can now artificially extend life, and this raises ethicolegal concerns. The recognition of living wills and enduring powers of attorney is to be welcomed by both doctors and patients. For patients, it means that they can be assured that their wishes will be carried out at the end of their lives, either by a person nominated to act on their behalf or through a living will. The proposed new law requires such decisions to be taken in a measured way based on medical advice, but respectful of their enduring right to autonomy. For doctors it is a lifeboat, as it provides certainty regarding their liability for the withholding or withdrawing of treatment. It is submitted that this Private Members Bill should be supported, as it provides legal certainty in the current sea of uncertainty.

Acknowledgements. None.

Author contributions. AS and SB prepared the first draft. SS assisted with researching the position in the ethical guidelines and $C B$ researched the issue of the weight that ethical guidelines carry in assessing the reasonableness of a medical professional's actions. All authors contributed to the overall editing.

Funding. None.

Conflicts of interest. None.

1. Health Professions Council of South Africa. Guidelines for the withholding and withdrawing of treatment 2016. Pretoria: HPCSA, 2016. https://www.hpcsa. co.za/Uploads/Professional_Practice/Conduct $\% 20 \% 26 \% 20$ Ethics/Booklet $\% 20$ 7\%20Guidelines\%20withholding\%20and\%20withdrawing\%20treatment $\% 20$ September\%202016.pdf (accessed 7 January 2019).

2. South Africa. National Health Act No 61 of 2003.

3. South African Medical Association. Living Wills and Advance Directives 2012. https://www.samedical.org/images/attachments/guidelines-with-regard-toliving-wills-2012.pdf (accessed 7 January 2019).

4. Clarke v Hurst NO and Others 1992 (4) SA 630 (D)

5. South African Law Reform Commission. Euthanasia and the artificial preservation of life. SALRC, 1998. http://www.salawreform.justice. gov.za /reports/r prj86 euthen_1998nov.pdf (accessed 3 September 2018).

6. South Africa. National Health Amendment Bill, No B29-2018, 2018.

7. Castell v de Greef 1994 (4) SA 408 (C).

8. South Africa. Constitution of the Republic of South Africa. 1996.

9. Pieterse M. The interdependence of rights to health and autonomy in South Africa. S Afr Law J 2008:125(3):553-572.

10. $A B$ and Another v Minister of Social Development 2017 (3) BCLR 267 (CC).

11. Pandie v Isaacs (A135/2013, 1221/2007) [2013] ZAWCHC 123 (4 September 2013).

Accepted 26 September 2019 